\title{
Publisher Correction: Microfluidic assessment of metastatic potential
}

Zhengpeng Wan and Roger D. Kamm D

Correction to: Nature Biomedical Engineering https://doi.org/10.1038/s41551-019-0412-5, published online 7 June 2019.

In the version of this News \& Views originally published, the wrong colour scale was used for 'Migratory (\%)' in the legend for panel b; this has now been amended. The corrected Fig. $1 \mathrm{~b}$ is shown below.

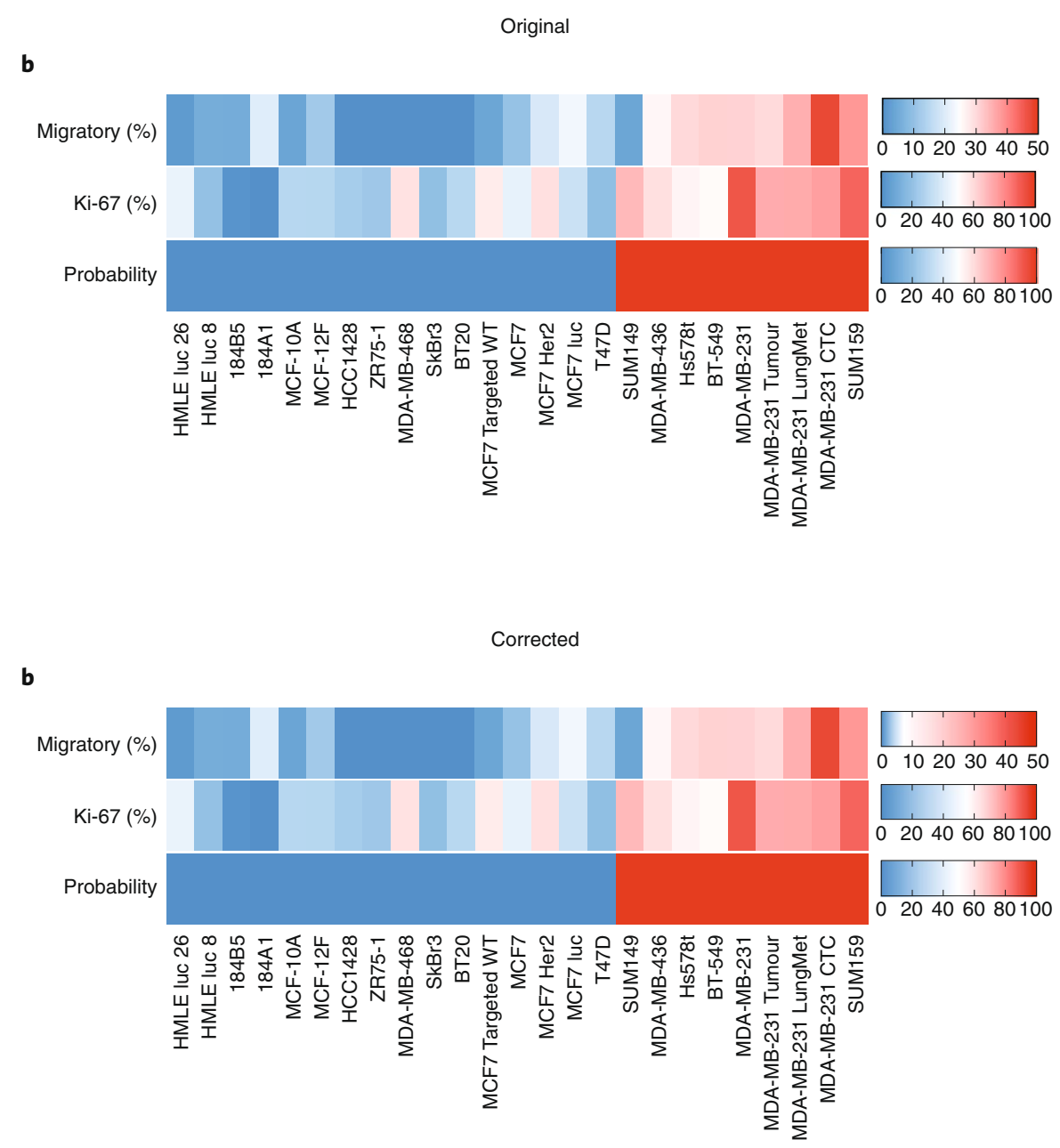

Fig. 1 | Original and Corrected. 